\title{
Hairy Root Induction in Linum mucronatum ssp. mucronatum, an Anti-Tumor Lignans Producing Plant
}

\author{
Afsaneh SAMADI ${ }^{1}$, Jirair CARAPETIAN ${ }^{1}$, Reza HEIDARI ${ }^{1}$, Morad \\ JAFARI ${ }^{2,3 *}$, Abdollah HASSANZADEH GORTTAPEH ${ }^{4}$ \\ ${ }^{1}$ University of Urmia, Faculty of Science, Department of Biology, Urmia, Iran \\ ${ }^{2}$ University of Urmia, Faculty of Agriculture, Department of Agronomy and Plant Breeding, \\ Urmia,Iran;m.jafari@urmia.ac.ir (*correspondingauthor) \\ ${ }^{3}$ University of Urmia, Institute of Biotechnology, Department of Agricultural Biotechnology, Urmia, Iran \\ ${ }^{4}$ Agricultural and Natural Resources, Research Center, West Azerbaijan, Iran
}

\begin{abstract}
Transgenic hairy root system is a promising source of secondary metabolites in medicinal plants with high pharmaceutical value. For the first time, hairy roots were established in different explants of Linum mucronatum, an anti-cancer agent producing plant, via a mikimopine type strain of Agrobacterium rhizogenes, 'A13'. The percentage of hairy root induction varied from 0 to $60 \%$ depended on the explants and hypocotyl (including cotyledonary node) explants were found to be highly susceptible to $A$. rhizogenes infection with the highest (60\%) rate of hairy root induction. four different Murashige and Skoog (MS)-based liquid culture media were used for well establishment of hairy roots. Hairy root growth medium D (HRGM-D) containing hormone-free MS basal medium with an extra one day pre-incubation period at $35^{\circ} \mathrm{C}$ was found to be more efficient for profuse growth (fresh weight; $8500 \mathrm{mg}$ per $25 \mathrm{ml}$ culture medium) of hairy roots. Hairy root system presented in this study may offer a suitable platform for optimization and production of satisfactory level of aryltetralin lignans like podophyllotoxin and its derivatives from L. mucronatum.
\end{abstract}

Keywords: Agrobacterium rhizogenes, explant, growth medium, medicinal plants, secondary metabolites

\section{Introduction}

Linum spp. from section Syllinum are promising for the production of aryltetralin lignans like podophyllotoxin (PTOX) and 6-methoxypodophyllotoxin (6-MPTOX) (Mohagheghzadeh et al., 2007). PTOX is the main lignan in the cell cultures of Linum album and 6-MPTOX is predominantly accumulated in cell lines of $L$. flavum, $L$. nodiflorum, L. mucronatum, and L. tauricum. This lignan and its derivatives possess anti-cancer properties (Ionkova, 2007). The semi-synthetic derivatives of this compound like etoposide, etophos, and teniposide are used clinically as chemotherapeutic agents for a variety of tumors, including small cell lung carcinoma, testicular cancer, and malignant lymphoma (Ionkova et al., 2010). Agrobacterium rbizogenes mediated transformation system was found to be very useful for hairy root induction and production of phytochemicals (Choi et al., 2000; Veena and Taylor 2007). Transformed roots of many plant species have been widely studied for the in vitro production of secondary metabolites (Christensen and Muller, 2009; Mukundan et al., 1998). Hairy roots are genetically stable and not repressed during the growth phase of its culture (Bourgaud et al., 1999). The greatest advantage of hairy roots is that their cultures often exhibit approximately the same or greater biosynthetic capacity for secondary metabolite production as compared to their mother plants (Kim et al., 2002). They can be a promising source for the continuous and standardized production of secondary metabolites under controlled conditions without losing genetic or biosynthetic stability (Giri and Narasu, 2000). They would be the best choice for metabolic engineering of the secondary metabolite pathways to enhance the accumulation and secretion of high value metabolites (Arroo et al., 2002). Even in cases where secondary metabolites accumulate only in the aerial part of an intact plant, hairy root cultures have been shown to accumulate the metabolites (Bakkali et al., 1997; Wheathers et al., 2005). Successful induction of hairy root has been reported in some Linum spp. such as L. flavum (Lin et al., 2003; Oostdam et al., 1993), L. austriacum (Mohagheghzadeh et al., 2002), L. leonii (Vasilev et al., 2006) and L. tauricum (Ionkova and Fuss, 2009) and main metabolites (Lignans) from resulted hairy roots have been shown to have biological activity. Based on the scientific literature currently available, there is no publication on the hairy root induction in $L$. mucronatum. Therefore, in this study, successful hairy root production of this species was achieved by Agrobacterium rhizogenes mediated transformation. In addition, the effects of culture media were also evaluated for the growth enhancement of hairy roots. 
126

\section{Materials and methods}

\section{Seed germination and explant preparation}

L. mucronatum seeds were collected from mountain region around the city of Tabriz, West Azerbaijan Province, Iran. The seeds were thoroughly washed under running tap water for $15 \mathrm{~min}$ and surface-sterilized by immersing in $70 \%(\mathrm{v} / \mathrm{v})$ ethanol for $1 \mathrm{~min}$ and in $2 \%(\mathrm{v} / \mathrm{v})$ solution of sodium hypochlorite (commercial bleach) for $10 \mathrm{~min}$. Finally, sterilized seeds were immediately rinsed with sterile distilled water for $10 \mathrm{~min}$ to wash out the sterilization agents before placing onto glass vessels containing $7.5 \mathrm{~g} / \mathrm{l}$ water-agar for germination. The cultures were maintained in a growth chamber at $24 \pm 2^{\circ} \mathrm{C}$ with a photoperiod of 16 $\mathrm{h}$ light and $8 \mathrm{~h}$ dark under light intensity of $40 \mu \mathrm{mol} / \mathrm{ms}$ ). The 4-week-old germinated seedlings were used as explant source. Different explants including cotyledon, hypocotyl (including cotyledonary node) and root were taken from the seedlings.

\section{Bacterial strain and plant transformation}

A mikimopine producing wild-type strain 'A13' of Agrobacterium rhizogenes, was used in the transformation, which was kindly provided by the National Institute of Genetic Engineering and Biotechnology, Iran. A single bacterial colony was cultured into liquid LB medium (Bertani, 1952) supplemented with $50 \mathrm{mg} / \mathrm{l}$ rifampicin and maintained at $28^{\circ} \mathrm{C}$ for $48 \mathrm{~h}$ on a rotary shaker at $200 \mathrm{rpm}$ speed. Transformation procedure was done as described previously (Jafari et al., 2009). The overnight grown bacterial culture was centrifuged at 3,500 rpm for $10 \mathrm{~min}$ and the bacterial pellet was re-suspended in liquid MS medium (Murashige and Skoog, 1962), pH 5.5. Final Density of bacterial suspension was diluted with LB medium to 0.4-0.6 OD (optical density at $600 \mathrm{~nm}$ ) before using for the infection. The isolated explants were cut into small pieces of about $5-10 \mathrm{~mm}$ and then were submerged in the bacterial suspension for $5 \mathrm{~min}$ with occasional shaking. The explants were blotted on a sterile filter paper to remove the excess bacterial suspension. Inoculated explants were transferred to agar $(7.5 \mathrm{~g} / \mathrm{l})$ solidified hormone-free MS medium for co-cultivation under dark incubation at $24 \pm 2^{\circ} \mathrm{C}$ for 2 days. As a control, a few explants were immersed in sterile distilled water and were cultured the same way. After 2 days, the explants were rinsed with sterile water to remove the bacteria from the surface and then transferred to MS medium supplemented with $500 \mathrm{mg} / \mathrm{l}$ of cefotaxime, $30 \mathrm{~g} / \mathrm{l}$ sucrose and $6 \mathrm{~g} / \mathrm{l}$ agar. The concentration of cefotaxime was gradually reduced in the subsequent sub-cultures and finally was completely omitted after $3^{\text {rd }}$ sub-culture.

\section{Establishment of hairy roots}

Numerous hairy roots emerged from the wound sites of explants. The hairy roots were separated from the ex- plant tissue and sub-cultured on agar-solidified hormonefree MS medium and maintained in growth chamber at $24 \pm 2^{\circ} \mathrm{C}$ in the dark. Rapidly growing hairy roots were transferred to $30 \mathrm{ml}$ of MS liquid medium, containing $30 \mathrm{~g} / \mathrm{l}$ sucrose, in $100 \mathrm{ml}$ Erlenmeyer flasks on a rotary shaker $(110 \mathrm{rpm})$ at $24 \pm 2^{\circ} \mathrm{C}$ in the dark and sub-culturing was carried out after every 14 days in the same medium for proliferation of hairy roots (Mohagheghzadeh et al., 2002) (Fig. 1).

\section{Polymerase chain reaction analysis for hairy roots}

Genomic DNA was extracted from both hairy roots and untransformed roots (control) by CTAB method (Khan et al., 2007). For confirmation of the transgenic nature of hairy roots, the presence of the rol genes located on the T-DNA which are main determinants for the development of hairy roots were examined by polymerase chain reaction (PCR) analysis using corresponding genespecific primer pairs. The $\mathrm{Ri}$ plasmid of $A$. rhizogenes strain 'A 13' was used as a positive control. The primer sequences to amplify a 1,794 -bp portion of the rol $A-B$ genes were 5'-CAGTTTCGCATCTTGACAG-3' and 5'-GTTCTCGCGAGAAGATGCA-3'. The PCR reaction conditions were as follows: initial denaturation for $5 \mathrm{~min}$ at $94^{\circ} \mathrm{C}$, followed by 35 cycles consisted of denaturation for $1 \mathrm{~min}$ at $94^{\circ} \mathrm{C}$, annealing for $1 \mathrm{~min}$ at $58^{\circ} \mathrm{C}$, extension for $1 \mathrm{~min}$ at $72^{\circ} \mathrm{C}$, and a further extension step for $10 \mathrm{~min}$ at $72^{\circ} \mathrm{C}$. Amplified DNAs were analyzed by staining with ethidium bromide after electrophoresis in a $0.8 \%(\mathrm{w} / \mathrm{v})$ agarose gel at $80 \mathrm{~V}$ for $90 \mathrm{~min}$.

\section{Treatment of hairy roots growth in liquid media}

Two to three weeks after the emergence of hairy roots, some of them were transferred to a fresh liquid MS basal medium including 3\% sucrose namely Hairy Root Growth Medium A (HRGM-A) as well as to three other media including HRGM-B, HRGM-C and HRGM-D containing MS basal medium supplemented with $0.2 \mathrm{mg} / \mathrm{l}$ $\alpha$-naphthalene acetic acid (NAA), hormone free MS medium with $2 \%$ sucrose, and the same as HRGM-A with pre-incubation at $35^{\circ} \mathrm{C}$ for $24 \mathrm{~h}$, respectively. All culturs were incubated in $100 \mathrm{ml}$ Erlenmeyer flasks on a rotary shaker $(110 \mathrm{rpm})$ at $24 \pm 2^{\circ} \mathrm{C}$ in the dark and after 2 weeks of incubation, the extent of development of hairy roots in terms of fresh weight (FW, mg/25 ml culture medium) was assessed.

\section{Statistical analysis}

Data for root weight were collected from four growth media treatments, each of them were set up in a completely randomized design (CRD) with three replicates per treatment. Data were subjected to the analysis of variance (ANOVA) using SAS computer package (SAS Institute Inc., 2004) and means differing significantly were compared using Fisher's least significant difference (Fisher, 1954 ) test at a $5 \%$ probability level. 


\section{Results and discussion}

\section{Induction of hairy root}

Transgenic hairy root system is of great importance, particularly in several economically important plants, like L. mucronatum, where transgenic plants are difficult to achieve. This investigation was able to establish hairy roots in this medicinal plant using $A$. rhizogenes strain 'A13'. Hairy root cultures were initiated from different inoculation sites (Fig. 1A-D) of used explants isolated from young seedlings of $L$. mucronatum after 2-3 weeks infection. The hairy roots had a suitable growth and prolific root development was evident after 8 weeks (Fig. 1E), whereas no adventitious roots formed from the control explants. Also, Agrobacterium-inoculated cotyledon explants did not show induction of roots (data not shown).

Hypocotyl explants were highly susceptible to infection by strain 'A13' of $A$. rhizogenes, as shown by the percentage $(60 \%)$ of them from which hairy roots emerged, whereas; root explants exhibited the lowest infection frequency (20\%). We did not find any hairy roots from cotyledonary leaves. The results indicated that wild type strain of $A$. rhizogenes used in this study were able to im-
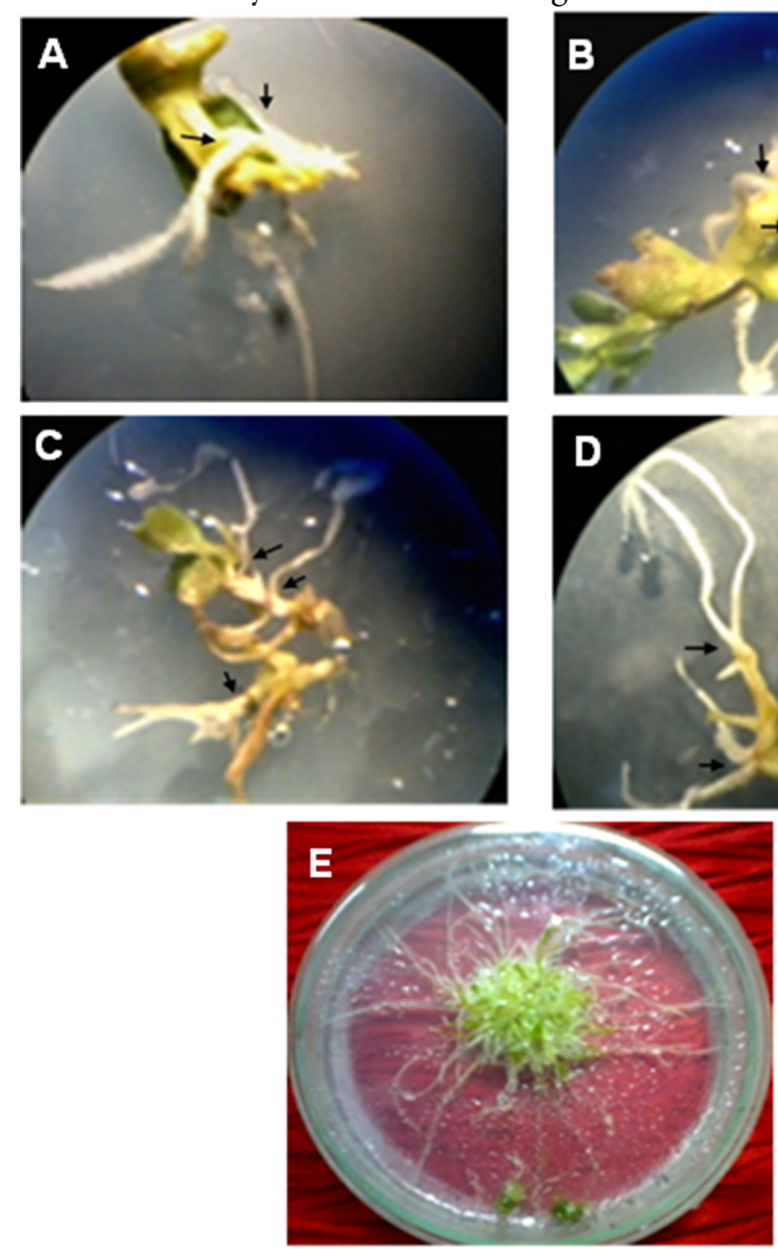

Fig. 1. Hairy roots induced on different sites of hypocotyl explants in $L$. mucronatum one week after inoculation by $A$. rbizogenes strain 'A13'. A-D: initiation and growth of hairy roots in phytohormone-free MS medium, Black arrows indicate sites of induction of hairy root, E: well development of hairy roots after $2^{\text {nd }}$ sub-culture into the same medium

pressively induce hairy roots on hypocotyl explants that can be used for mass production of hairy roots in $L . m u$ cronatum. In general the variation in hairy root induction could possibly be attributed to the variation in virulence of different Agrobacterium strains as well as to plant species and type of explant used in transformation (Porter, 1991). In L. flavum, hairy roots were initiated from leaf discs with a success rate of approximately $50 \%$ using $A$. rhizogenes strains, 'LBA9402'and 'TR105'. In contrast, very low hairy root induction rates were obtained with strains '15834' and 'A4' (Lin et al., 2003). Evidently, the selection of an effective Agrobacterium strain for the production of transformed root cultures is highly dependent on the plant species, and must be determined empirically (Lee et al., 2010). Therewith, the results of the present study with consistent to previous research showed definite role of explant type in efficient transformation rate and prolific hairy root induction.

Successful production of hairy roots via wild type strain 'A13' of A. rbizogenes has been also reported in several medicinal plant species by other workers. For instance, the epicotyl explants derived from mature embryo axis of groundnut were infected with strain 'A13' of $A$. rhizogenes
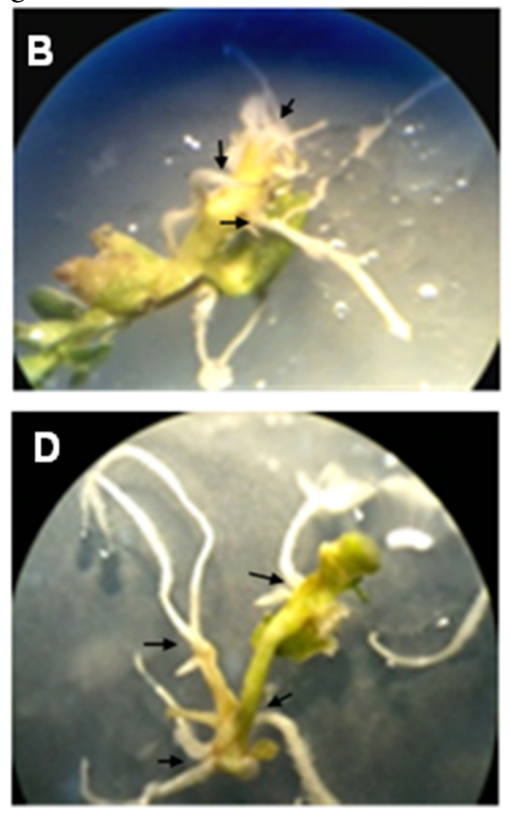

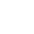


128

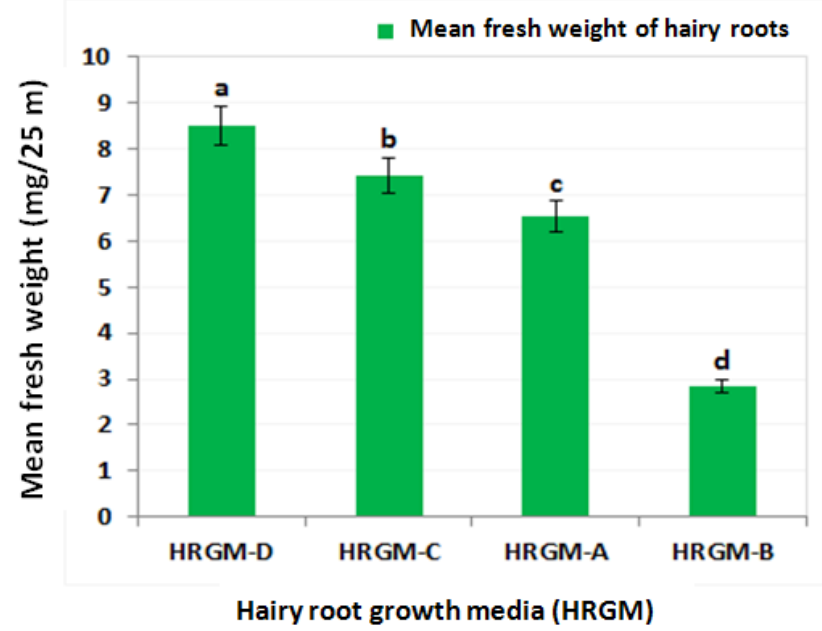

Fig. 2. Effects of various culture media on the growth of transgenic hairy root lines produced by $A$. rhizogenes strain 'A13' in L. mucronatum. The bars represent means \pm SE. Bars followed by different letters are significantly different $(p<0.05)$ according to FLSD

produces hairy roots (Akasaka et al., 1998). Ohara et al. (2000) reported hairy roots induction from leaf segments of Crotalaria juncea, by infection with a mikimopine type wild strain 'A13' of $A$. rhizogenes. Regeneration of plants from hairy roots induced by strain 'A 13 ' of $A$. rhizogenes is well established and has been reported in different medicinal plants as well (Akutsu et al., 2004; Fukuda et al., 2007; Godo et al., 1997; Handa, 1992; Ishizaki et al., 2002; Koike et al., 2003, Ohara et al., 2000).

\section{Effect of culture media in hairy root growth}

The secondary metabolite synthesis in hairy roots is influenced by nutritional and environmental factors. Exogenous growth phytohormone, the sucrose level, the nature of nitrogen source and their relative amounts, light, temperature and the presence of chemicals can all affect the growth and total biomass yield and secondary metabolite production. Optimization of these components would enhance the production of desired secondary me- tabolites. There are several reports indicating that sucrose and/or auxin supplementation could stimulate higher levels of hairy root production (Nilsson and Olsson, 1997; Sato et al., 1991; Yoshikawa and Furuya, 1987). In this study, rapidly growing hairy roots were cultured in four different liquid media for 21 days. The rate of proliferation showed significant $(p<0.05)$ difference between the media in terms of hairy root fresh weight (Fig. 2), since the fresh weight of the hairy root cultures increased from low level of the original inoculum to $2.8-8.5 \mathrm{~g} / 25 \mathrm{ml}$ varied between HRGM media in a 3 weeks culture period. The results showed that HRGM-D was the best medium for well improvement of hairy root growth $(8500 \mathrm{mg} / 25 \mathrm{ml}$ fresh weight). The superior effect of a pre-incubation at $35^{\circ} \mathrm{C}$ on hairy root growth is shown in Fig. 3. In contrast, the hairy roots cultured on auxin ( $0.2 \mathrm{~g} / \mathrm{l} \mathrm{NAA})$-supplemented medium (HRGM-B) did not grow well and had the lowest $(2800 \mathrm{mg} / 25 \mathrm{ml})$ level of fresh weight compared with the other media. Susumu et al. (1996) also reported the little effect of auxins on hairy root growth. However, it was demonstrated more recently that when testing systematically the effect of different types of phytohormones upon root growth and secondary metabolite production, some of them could enhance either growth or metabolites production. In the case of Artemisia annua hairy roots (Wheathers et al., 2005), the response of cultures to five types of hormones: auxins, cytokinins, ethylene, gibberellins (GA) and abscisic acid (ABA) was evaluated. The highest biomass was obtained when $1-5 \mathrm{mg} / \mathrm{l} \mathrm{ABA}$ was supplied in the medium, while $0.5-1 \mathrm{mg} / 1$ 2-isopentenyladenine (ipt) inhibited root growth but stimulated the production of artemisinin more than 2 -fold.

\section{Detection of relevant transgenes in the selected hairy root lines}

Hairy root induction is due to the integration and subsequent expression of a portion of Transferred DNA ( $T$ DNA) from the bacterial Ri (Root inducing) plasmid in the plant genome (Christensen and Muller, 2009). Four loci involved in root formation have been identified in the
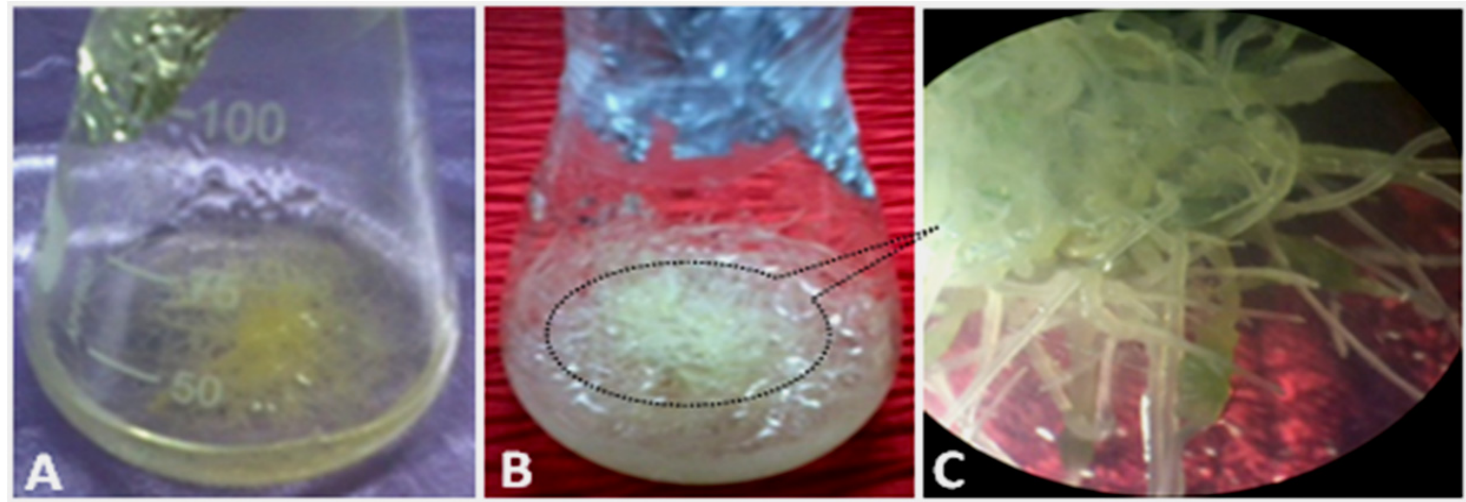

Fig. 3. Effect of high incubation temperature $\left(35^{\circ} \mathrm{C}\right)$ on hairy roots growth. A: One pair of hairy roots at the beginning of treatment, B: Appearance of hairy roots 2 weeks after treatment, C: A close-up picture from plentiful growth of hairy roots 


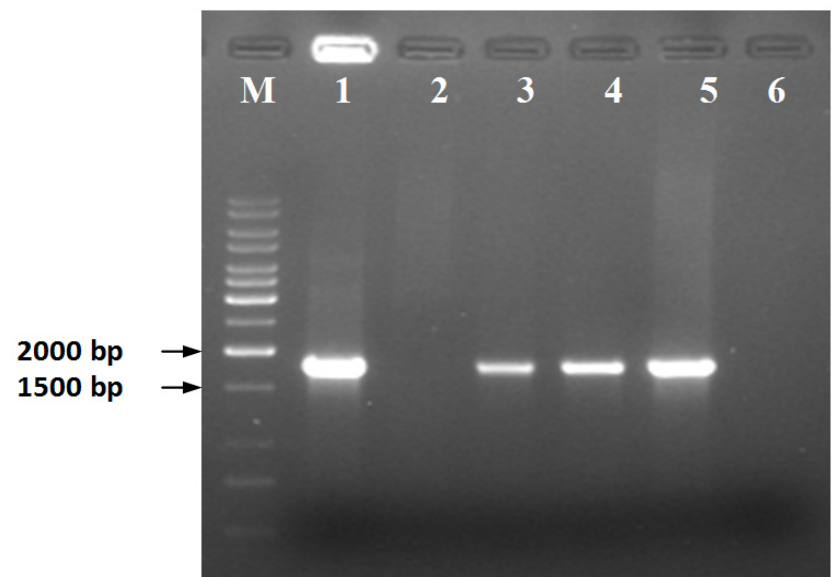

Fig. 4. PCR analysis for hairy roots lines of L.mucronatum using the $\operatorname{rol} A$ and $r o l B$ genes specific primers. M: $1 \mathrm{~Kb}$ DNA Ladder (Fermantas), 1: Ri plasmid from $A$. rhizogenes strain 'A13' as a positive control, 2: Wild plant root as first negative control, 3 to 5: Transgenic hairy roots induced on hypocotyl and root explants infected by Agrobacterium, 6: Non-DNA template PCR reaction as second negative control

T- DNA of the Ri plasmids and designated root loci (rol) A, B, C and D (Ayala-Silva et al., 2007). The rolB gene is absolutely essential for the induction of hairy roots. Even when expressed alone, the $\operatorname{rol} B$ gene can induce significant hairy roots production (Nilsson and Olsson, 1997). Successful genetic transformation can be demonstrated in direct or indirect ways by detecting opines or T-DNA sequences, respectively. The direct method is preferred as in some cases. Nonetheless, opines production is not stable and may even cease (Sevon and Oksman-Caldentey, 2002). PCR method can be used simply for detecting T-DNA sequences in putative transformants (Palazon $e t$ al., 2003). In this study, the presence of the rol $A$ and rolB genes in the hairy root lines was confirmed by PCR analysis (Fig. 4) using primers specific for core sequence located between the $\operatorname{rol} A$ and $r o l B$ genes. In the selected transgenic hairy root lines, a sharp band of 1794-bp was amplified, but no such amplicon was observed in the untransformed root (negative control) sample. This result indicated that L. mucronatum is susceptible for transformation with Agrobacterium rhizogenes strain 'A13' and the roots and hypocotyls explants respond quite efficiently to transformation by Agrobacterium.

\section{Root morphology}

Transformed and untransformed roots were strikingly different in morphology and growth. The hairy root lines were characterized by vigorous growth and abundant lateral branching (Fig. 1E). They also formed a callus in phytohormone-free medium (Data are not shown). These are a typical characteristic for hairy roots induced by wild type strain 'A13' of $A$. rhizogenes mediated transformation that have also been reported by some researchers (Akutsu et al., 2004; Fukuda et al., 2007; Ishizaki et al., 2002; Ohara et al., 2000). In addition, they had fast growth rates; the ratios of their final fresh weights to their initial fresh weights were greater than each generation of subculture. By contrast, untransformed roots did not branch and they had slow growth. It is also worth a note that transformed roots grew well in a hormone-free medium, while untransformed roots hardly grew in the same conditions (Fu et al., 2005), consistently in this study observed their plentiful growth on hormone free HRGM media. It must be noted that hairy root morphology of the primary cultures also can be variable. This could be due to slight differences in wound-induced phytohormone production or to differences in rol genes expression (Palazon et al., 1998).

\section{Conclusions}

The present study reports the successful production of transgenic hairy root lines in L. mucronatum. This report is the first, demonstrating the induction of hairy roots in this Linum species. The 'A13' strain of $A$. rhizogenes was capable of transforming hypocotyl (including cotyledonary node) and to some extent root explants, however, the relative efficiencies varied considerably between the explants. The results suggested that hypocotyl segments with high transformation rate $(60 \%)$ were as responsive explants for production of transgenic hairy roots in L. mucronatum and the use of a phytohormone-free MS basal medium with a one-day pre-incubation at $35^{\circ} \mathrm{C}$ increased prominently hairy root growth. Hairy root induction protocol presented in this research could be used for further optimization with regard to various operational factors influencing the enhanced production of pharmaceutical metabolites like podophyllotoxin in this valuable wild Linum species. Additionally, this transformation method could also be applied as an alternative to $A$. tumefaciens system for genetic engineering of this plant using heterologous genes for biotechnological uses and enhanced production of bioactive compounds.

\section{Acknowledgments}

The authors thank Dr. MA Malboobi (National Institute of Genetic engineering and Biotechnology, Iran) for kindly providing the $A$. rhizogenes 'A13' strain. Thanks are also extended to the Biotechnology Instiute of Urmia University (BIUU) for utilizing its laboratory facilities to execute this study.

\section{References}

Akasaka Y, Mii M, Daimon H (1998). Morphological alterations and root nodule formation in Agrobacterium ribzogenesmediated Transgenic hairy roots of peanut (Arachis hypogaea L.). Ann Bot 81:355-362.

Akutsu M, Ishizaki T, Sato H (2004). Transformation of the monocot Alstroemeria by Agrobacterium rhizogenes. Mol Breeding 13:69-78.

Arroo RRJ, Alfermann AW, Medarde M, Petersen M, Pras N, 
130

Woolley JG (2002). Plant cell factories as a source for anticancer lignans. Phytochem Rev 1:27-35.

Ayala-Silva T, Bey CA, Dortch G (2007). Agrobacterium rhizogenes mediated transformation of Asimina triloba L. cuttings. Pakistan J Bio Sci 10:132-13.

Bakkali T, Jaziri M, Foriers A, Vander HY, Vanhaelen M, Homes $\mathrm{J}$ (1997). Lawsone accumulation in normal and transformed cultures of henna, Lawsonia inermis. Plant Cell Tiss Organ Cult 51:83-87.

Bertani G (1952). Studies on lysogenesis. I. The mode of phage liberation by lysogenic Escherichia coli. J Bacteriol 62:293300.

Bourgaud F, Bouque V, Guckert A (1999). Production of flavonoids by psoralea hairy root cultures. Plant Cell Tiss Org 56:97-10.

Choi SM, So SH, Yun SR, Kwon OW, Seon JH, Paek KY (2000). Pilot-scale culture of adventitious roots of ginseng in a bioreactor system. Plant Cell Tiss Organ Cult 62(3): 187-193.

Christensen B, Muller R (2009). The Use of Agrobacterium rhizogenes and its rol genes for quality Improvement in Ornamentals. Europ J Hort Sci 74:275-287.

Fisher RA (1954). statistical methods for research workers. Oliver and Boyd, Edinburgh, 307 p.

Fu CX, Zhao DX, Xue XF, Jin ZP, Ma FS (2005). Transformation of Saussurea involucrata by Agrobacterium rhizogenes: Hairy root induction and syringin production. Process Biochem 40:3789-3794.

Fukuda KI, Daimon H, Mishiba KI, Mii M (2007). Histological observation of root bud formation of hairy roots in Lotus corniculatus L. Grassland Sci 53:51-53.

Giri A, Narasu ML (2002). Transgenic hairy roots recent trends and applications. Biotechnol Adv 18:1-22.

Godo T, Tsujii O, Ishikawa K, Mii M (1997). Fertile transgenic plants of Nierembergia scoparia Sendtner obtained by a mikimopine type strain of Agrobacterium rhizogenes. Sci Hort 68:101-111.

Handa T (1992). Regneration and charaterization of prairie gentian (Eustoma grandiflorum) plants transformed by Agrobacterium rhizogenes. Plant Tiss Cult Lett 9:10-14.

Ionkova I (2007). Biotechnological Approaches for the Production of lignans. Phcog Rev 1:57-68.

Ionkova I, Antonova I, Momekov G, Fuss E (2010). Production of podophyllotoxin in Linum linearifolium in vitro cultures. Pharmacogn Mag 6:180-185.

Ionkova I, Fuss E (2009). Influence of different strains of Agrobacterium rhizogenes on induction of hairy roots and lignan production in Linum tauricum ssp. Tauricum. Pharmacogn Mag 5:1418.

Ishizaki T, Hoshino Y, Masuda K, Oosawa K (2002). Explants of Ri-transformed hairy roots of spinach can develop embryogenic calli in the absence of gibberellic acid, an essential growth regulator for induction of embryogenesis from non-transformed roots. Plant Sci 163:223-231.

Jafari M, Norouzi P, Malboobi MA, Ghareyazie B, Valizadeh M, Mohammadi SA, Mousavi M (2009). Enhanced resistance to a lepidopteran pest in transgenic sugar beet plants expressing Synthetic crylAb gene. Euphytica 165:333-344.

Khan S, Irfan QM, Kamaluddin AT, Abdin MZ (2007). Protocol for isolation of genomic DNA from dry and fresh roots of medicinal plants suitable for RAPD and restriction digestion. Afr J Biotechnol 6:175-178.

Kim Y, Wyslouzil B, WeathersPJ (2002). Secondary methabolism of hairy root cultures in bioreactors. In Vitro Cell Dev Pl 38:1-10

Koike Y, Hoshino Y, Mii M, Nakano M (2003). Horticultural characterization of Angeloniasalicariifolia plants transformed with wild-type strains of Agrobacterium rbizogenes. Plant Cell Rep 21:981-987.

Lee SY, Kim SG, Song WS, Kim YK, Park NI, Park SU (2010). Influence of different strains of Agrobacterium rbizogenes on hairy root Induction and production of alizarin and purpurin in Rubiaakane Nakai. Rom Biotech Lett 15:54055409.

Lin HW, Kwok KH, Doran PM (2003). Development of Linum flavum hairy root cultures for production of coniferin. Biotechnol Lett 25:521-525.

Mohagheghzadeh A, Schmidt TJ, Alfermann AW (2002). Arylnaphthalene lignans from in vitro cultures of Linum austriacum. J Nat Prod 65:69-71.

Mohagheghzadeha A, Gholamia A, Hemmatia S, Shams Ardakanic MR, Schmidtd TJ, Alfermann AW (2007). Root Cultures of Linum Species Section Syllinum as Rich Sources of 6-Mothoxypodophyllotoxin. Z Natuforsch C 62:43-49.

Mukundan U, Rai A, Dawda H, Ratnaparkhi S, Bhinde V (1998). Secondary metabolites in Agrobacterium rbizogenes mediated transformed root cultures. Plant tissue culture and molecular biology applications and prospects. Narosa Publishing House, New Delhi.

Murashige T, Skoog F (1962). A revised medium for rapid growth and bioassays with tobacco tissue cultures Physiol plantarum 15:473-497.

Nilsson O, Olsson O (1997).The role of the Agrobacterium rhizogenes rol genes in the formation of hairy roots. Physiol Plantarum 100:463-473.

Ohara A, Akasaka Y, Daimon H, Mii M (2000). Plant regeneration from hairy roots induced by infection with Agrobacterium rbizogenes in Crotalaria juncea L. Plant Cell Rep 19:563-568.

Oostdam A,MolJNM,Vonder PlasLHW(1993).Establishment of hairy roots cultures of Linum flavum producing the lignan 5-methoxypodophyllotoxin. Plant Cell Rep 12:474-477.

Palazon J, Cusido RM, Gonzalo,Bonfill M, Morales C, Pinol MT (1998). Relation between the amount of rolC gene product and indole alkaloid accumulation in Catharanthus roseus transformed root cultures. J Plant Physiol 153:712- 
718.

Palazon J, Mallol A, Eibl R, Lettenbauer C, Cusido RM, Pinol MT (2003). Growth and ginsenoside production in hairy root cultures of Panax ginseng using a novel bioreactor. Planta Med 69:344-349.

Porter JR (1991). Host range and implications of plant infections by Agrobacterium rhizogenes. Crit Rev Plant Sci 10:387-421.

SAS Institute (2004). SAS/STAT user's guide. SAS Institute Inc., Cary, NC, USA.

Sato K, Yamazaki T, Okuyama E, Yoshihira K, Shimomura K (1991). Anthraquinone production by transformed root cultures of Rubiatinctorum: Influence of phytohormones and sucrose concentration. Phytochem 30:1507-1510.

Sevon N, Oksman-Caldentey KM (2002). Agrobacterium rhizogenes-mediated transformation: root cultures as a source of alkaloids. Planta Med 68:859-868.
131

SusumuS, TakashiY,Steven M, MichaelM(1996).Establishment of hairy root cultures ofchillipepper (Capsicum frutescens). Plant tissue culture letters 13:219-221.

Vasilev N, Elfahmi E, Bos R, Kayser O, Momekov G, Konstantinov S, Ionkova I (2006). Production of justicidin B, a cytotoxic arylnaphthalene lignan from genetically transformed root cultures of Linum leonii. J Nat Prod 69:1014-1017.

Veena V, Taylor CG (2007). Agrobacterium rhizogenes: recent developments and promising applications. In Vitro Cell Dev-Pl 43:383-403.

Wheathers PJ, Bunk G, McCoy MC (2005). The effect of phytohormones on growth and artemisinin production in Artemisia annua hairy roots. In vitro Cell Dev-Pl 41:47-53.

Yoshikawa T, Furuya T (1987). Saponin production by cultures of Panax ginseng transformed with Agrobacterium rhizogenes. Plant Cell Rep 6:449-453. 